\title{
THE SOCIAL SCIENCES AND THE SOCIALLY OPPRESSED IN AFRICA
}

\author{
Morris Edogiawerie \\ doi: http://dx.doi.org/10.4314/og.v8i1.8
}

\begin{abstract}
Many scholars have contended that Africa is underdeveloped most probably in comparison with other continents of the world. Some have concluded that there are many obstacles inhibiting the dire desire for development in Africa. Prominent amongst these problems is the issue of the oppression and suppression of the poor and less privileged in the society. The social sciences is one of the disciplines charged with the responsibility of studying the situation of the socially oppressed and suppressed in any society and finding ways of improving the lot of this majority of people. This paper will, therefore, inter alia, attempt a philosophical survey of the success or otherwise of the social sciences in efficiently studying the situation of the oppressed and suppressed in the African society and professing ways of creating a better Africa for all and sundry.

Key words: Injustice, Inhumanity and a better Africa
\end{abstract}

\section{Introduction}

Karl Marx, in his historical dialectics, clearly advocated there is a struggle between the bourgeoisie capital owners and the lumpeon proletariat who represent the owners of the labour and work force needed for the production of goods and services. According to this dialectics, the bourgeoisie class wants to continue to remain on top of the social class and control the means of production for as long as possible while maximizing the surplus-profit, of their investments without taking the interest of the proletariat into consideration.

On the other hand, the proletariats would not want to remain under the control and oppression of the bourgeoisie class simply because they do not own any means of capital because of their economic situation. The proletariat would want the bourgeoisie to know that without them in the chain of production, nothing meaningful and worthwhile would be achieved and thus their economic situation of the bourgeoisie, will be as bad as their own- 
the proletariat. Therefore, the struggle to overthrow each other is ceaselessly on and the struggle continues until an antithesis and a synthesis occur.(Kemenka, 1979)

Despite this endless struggle to overthrow each other, the fact remains that the population of the socially oppressed and suppressed in the African society is quiet large and even on the increase, and as it were, it has had a negative impact on the efforts towards development and advancement of the continent. The argument is that if this continues the continent will remain underdeveloped for a very long time and she would ultimately end up been left behind in the march towards globalization.

This paper will adopt a combination of both the a priori and a posteriori approach in examining the problem of social oppression, as it appears to be a clog in the wheel of development in Africa. To this end, it would be expedient to do the following, determine the meaning and nature of the social sciences; this will put us in a good stead at comprehending and appreciating whether or not the social sciences actually have a role to play in improving the situation of the socially oppressed in Africa. It would then be wise to find out the nature and problems of the social sciences. Thereafter, it will be the turn of determining whether the social sciences have actually succeeded in studying the situation of the socially oppressed in the African society. A critique and conclusion will follow as a roundup for a better and more comfortable Africa.

\section{The Meaning of Social Sciences}

Defining the phrase "social sciences" in one simple sentence such that the definition will be timeless and cross-cultural is not easy task due to the complexity of the phrase itself. The phrase or term is compound in nature. A decent attempt that will not end up been too metaphysical and therefore too abstract or too inorganic and therefore, meaningless must ipso facto involve the clarification of each of the two individual words separately i.e. 'social' and 'sciences'. The term 'social' has been variously referred to as that which concerns itself with issues of the human society, its organization or quality of life. ${ }^{2}$ Put differently, it is a concept that involves a discursive about a society especially, that of human beings in their interactive environment. It concurs with Aristotle's 
assertion that "man is a social animal". (Lloyd, G.E.R. 1973) who continually interact with his fellow man and his environment.

Man has not, does not and will not exist in a vacuum but in a life-world, which comprises of divers entities and phenomena beings and objects which require interaction and interpretation. In the process of meeting up with his immediate and remote needs, Dasein (Unah, 2002) finds out that he is needful of those things around him and most often, they are things within the reach of other men whom he most engage directly or indirectly to meet these needs. In other words, man must encounter and interact with his environment in order to be creative and find relevance. In the process of interaction, his social nature is exposed. It can therefore be concluded that the term 'social' depicts the organization and nature of Human beings as they interact and exist collectively rather than individually. Hence, a social society is one, which is made of Human elements in their interactive selves.

Meanwhile, science is said to have two senses of meaning; the broad and the narrow or restricted sense. In its broad sense, 'science' can be defined as "the systematic study of anything according to certain intrinsic principles. Any study carried out systematically and rigorously can be regarded as scientific knowledge" (Omorebge, 1998) It is thus obvious that any body of knowledge acquired through the use of certain careful intrinsic principles together with some rigorosity and systematicity is regarded as scientific knowledge. From this definition, such disciplines like literature, art, drama, etc. can be regarded as scientific disciplines, unlike the natural or physical sciences, which many refer to as the one and only true science.

In the narrow or restricted sense, science has been defined as the study, which involves the careful observation, experimentation, sense experiential and evaluation of the natural or physical world, and this conventionally, is ascribable to such disciplines as physics, chemistry and biology. Science in the restricted or narrow sense is subject to a series of rigorous testing, self-scrutiny and the verification of facts as they correspond with existence. One of the uniqueness of this kind of science is that the degree of its outcome is often very highly accurate, universal and transparent i.e. that the findings of scientific enquiry is naturally that of finality and high 
predictability. The results of science in a restricted sense which progress from hypothesis to theories, to laws, explanations are explicable in the letters Q.E.D. (Quod erat demonstrandum), meaning that the testability is universal and final. Also in the broad sense, science has been defined as "the study of knowledge which can be made into a system that depends on the seeing and testing of facts, and the stating of general natural laws..."By and large, in whatever manner science is defined, the bottom-line is that certain basic principles are involved.

Sequel to the above conceptual clarification of the rather complex phrase "social sciences", it appears that the discipline is a descriptive one. As a descriptive discipline, it can be regarded as a science, which studies man and his activities in relation to others in the society. The social sciences claim to employ the natural scientific methods in its study of the human society. It also claims that it does not only study the human elements in the society but also the physical and psychological elements as well. Another major claim of the social sciences is that it can and does study the human society objectively, making predictions concerning human behavior based on the inductive facts available to it.

\section{The Nature and Problems of the Social Sciences}

The social sciences are quite different from the natural or physical sciences because of the object-Humans, and methodology of its study. As a descriptive discipline, the social sciences claim it can 'philosophically' apply the variables of the natural sciences in the study of the human society. However, unlike the natural sciences, whose hypothesis can be tested and verified in laboratories that of the social sciences cannot be subject to such tests and verification. The social sciences cannot boast of the capacity of making definite and universal predictions with a high degree of precision, which the physical sciences can. The high degree of precision and accuracy of the natural sciences is certain and applicable with such finality everywhere in the world with the exact same parameters put in use until such a time when that hypothesis or theory is scrutinized and proven obsolete and outdated. Thus, the hypothesis and theories of the natural sciences can be taken as Q.E.D. This is not possible with 
the social sciences because their professed theories and hypothesis and thus outcomes are not accurate and constant.

Human beings, who are the primary object of study of the social sciences are highly unpredictable and erratic in nature. This factor makes the analysis and evaluation and findings of the social sciences unpredictable and inaccurate. Besides been unpredictable and erratic, human beings have feelings and emotions which non-living objects do not have, and these emotions and feelings impede the judgments and decision of men. Human beings are bound to put themselves into whatever they are involved with at a particular time. Moreover, human beings have a mind and the ability to make choices, which objects do not have. Largely, humans are valued laden i.e. that they have aversion and a kind disposition to different things at different times. This ultimately results in the attachment of sentiments and bias in almost all their activities and the decisions they make. All these facts make it extremely difficult for the social sciences to study the true and concrete nature and situation of man. Therefore, the findings of the social sciences are inconsistent, faulty and falsifiable.

Further, these salient factors inherent in humans go a long way in affecting the inductive methodology, which the social sciences employ in arriving at results. For example, in the natural sciences, if it is true that water boils at $100^{\circ} \mathrm{F}$ in Nigeria then the same apply everywhere in the world at that same temperature and condition. It is a given anywhere. This is not so with the social sciences because, for instance, if certain parameters were applied in a place during elections in England and a certain party won the elections as a result, it does not follow that the same thing will happen in Nigeria if the same procedure is followed and that the desired party will win the elections. The situation and prevailing circumstances will never be the same in both countries at the same time. Another example is a man who has stomach upset and needs to use the convenience urgently, yet pretends all is well with him and sits tight in a board meeting wanting to be privy to all the proceedings. His decisions and judgments will differ from that of a man who is relaxed and comfortable.

Sequel, the claims of the social sciences in being able to make generalizations which is supposed to describe facts about the human society does not always turnout the same as that of the physical 
sciences. Yet the social sciences claim to have laws like the natural sciences. They contend if the natural sciences have laws like the Boyles law, Charles law, Newton's law etc. then they too have laws like that of diminishing returns, laws of demand and supply, psychological laws etc. Despite the laws of the social sciences, the degree of precision is not guaranteed. For example, the laws of demand and supply do not always hold in every situation and circumstance, and the laws of the social sciences have frequently failed upon testing and verification. The fact that there is always an interest at the background, either consciously or unconsciously cannot be denied and this goes a long way in determining the passing of value judgment. Like mentioned before, humans are always part of what they do or get involved with.That is, that we are always part of what we do or interact with.

This brings us to the issue of what ethical and social structures consist of. For Radcliffe, "social structures" involves "an arrangement of persons in institutionally controlled or defined relationship". This means that the term refer to social organizations with actual individuals as its constituents. In Evans Pritchard's view, it is taken to mean the exclusion of relations between persons, but to describe such relations between groups as having a high degree of constancy and consistency. It may also be taken in a still more abstract sense as a network of relationship between sets of institutionalized social roles. (Pitchard, 1957)

Providing a detailed theoretical framework will eventually lead us to the examination of the role and status of the individual in the social societal structure but for the purpose of this work, we shall not delve into that in the social sciences i.e. the invasion of privacy, protection of research data, and the issue of informed consent and cross-cultural studies. (Sills, 1973).

\section{The Social Sciences and the Socially Oppressed in Africa}

For the purpose of comprehension and appreciation of the issue at hand, the beginning of this sub-section shall be devoted to examining the concept of oppression and suppression and how well the social sciences has succeeded in studying and proffering answers to the problems of the socially oppressed in African. Therefore, it would be prudent to ask what are oppression and suppression and 
who are the oppressed and oppressors. To define the word is to define oppress because of the suffix 'sion'. Hence, to oppress means, "to rule or treat somebody with continual injustice or cruelty...to cause to feel ill or bad" (Hornby, 2007). It can also be seen as wickedness, denial, especially of those rights that are relevant to human comfort, happiness and fulfillment. Anyone or group of persons that have been treated in this fashion is (are) known as the oppressed, and such people are less advantaged, less influential, poor, less powerful and unheard. Thus, oppression is the exercise or display of raw power by the powerful over the less powerful or weak. A good example is colonialism and imperialism.

Sequel to the above, the oppressor is the one who derive pleasure in ill-treating others or denying them their rights, treating them unjustly, wickedly or cruelly. It is man's inhumanity to man and his injustice to his fellow men. Man invented oppression. It is not a natural phenomenon. Hobbes clearly stated this when he discussed the state of nature, which he described as, nasty, solitary, brutish, poor and short". (Appadorai, 1982) The oppressed and the suppressed are those who suffer in the hands of the oppressor(s). They are those who are at the receiving end. Some scholars call them the subalterns.

Having identified the oppressor and the oppressed, let us now examine how well the social sciences have succeeded in studying and understanding the situation of the socially oppressed, suggesting a better existence for them as a way of eliminating the injustice and inhumanity melted on them by their fellow men. The object of study of the social sciences in Africa is the same everywhere and anywhere in the globe. Therefore, if there are problems in Africa then the situation is seldom different from other places, hence, there is no perfect or ideal human society. In its study the social sciences does not only focus attention on the human elements but also on the physical, psychological and other factors that relate to him and affect him. Prominent amongst scholars who have studied the behavioral patterns of man are Sigmund Freud, Auguste Comte, Emile Durkheim, etc. (Omoregbe, 1998) The social scientists consider some very intrinsic features which determine human behavior, such as the elements of emotions, pretence, bias, deception, ambition, self-interest, pride, value attachment etc. The 
social sciences has hardly succeeded, for instance, because it always very difficult to tell why a man may not show restiveness when the truth is that he is extremely hungry or psychologically disturbed. He might want to fool or deceive those around him into believing that all is well with him when the situation is actually the opposite. There could be a thousand and one reasons why he is actually feigning. For instance, he might want to prove that he can withstand extreme conditions when actually he does not have to prove anything. One can be suffering greatly and yet not complain about it. Such a person might not see anything wrong with the hard times he is experiencing and as such refer to it as part of life.

In Africa, nonetheless, the case is more peculiar and pathetic. Some social scientists contend that the problem is with the orientation of Africans. Some others argue that colonialism has a lot to do with the problem of social oppression and suppression because the colonial mentality that their colonial overlords left behind has been deeply implanted in them. The few educated elites saw it as their right to be worshipped and served just like they served their masters by virtue of the fact that they were educated and therefore superior to those their black brothers that were not educated. This mentality has culminated into many other issues that have eaten deep into dire need to advance as a continent like any other continent of the world. This mentality like cancer has led to corruption, insensitivity, unpatriotism, immorality, etc. The oppressors who comprise of the capitalists and the bourgeoisie elites have devised ways of endlessly ensuring that the oppressed remain oppressed so that they will continually remain on top and control their affairs with little or no questions asked. For instance, they have left them starved and deprived of the basic amenities of life. This oppressor class diverts public funds to personal use and thereby keeps the people impoverished. This goes a long way in explaining the poverty and starvation in the African continent. There is also the problem of disease and backwardness resulting from the lack of infrastructural development.

Besides the above problems, African leaders openly oppress their people by wanting to cling unto power and have their every desire imposed on the people for as long as possible. Despite the clamor by other continents of the world, to democratize, African 
rulers and leaders do not see any need for democracy as they want to hang on to power for as long as 35 to 45 years, even permanently. Thereafter which they hand over to their children or close relative to continue their legacies and policies. The social scientists in studying Africa will make the relevant impact if they will take the pains to understand the basic problems confronting the people. Oppression is bound to result in every capitalist society because there is an inequality among men who live together, share the same religion, economy, politics and supposedly the same social status. A socially oppressed individual is a man who is deprived of every constructive ideal including the very possibility of an ideology. Social Oppression is slavery of man in the very highest order. If John Rawls were to be a social scientist then he has taken a deep look at the issue of social oppression in his famous treaty titled "A THEORY OF JUSTICE" (1952). The argument here is that no known African social scientist has done any recognized work to address the problems bedeviling the African continent with particular attention to the debacle of social oppression and suppression. In other words, no particular attention has been paid by any social scientist, especially African social scientists to study and understand the social problems of Africa and find ways of solving them.

An American president once said, "Power corrupts and absolute power corrupts absolutely". Iroegbu also posited that he that has power has everything because power is everything. All is power and power is all. (Iroegbu, 2000) If the postulations of Hobbes and Machiavelli were to adopted then we would have absolute rulers who would unleash terror on the state without anyone stopping them. Social scientists must try to enlighten the masses on the need for insisting that they take active part in the affairs that concern them directly. If the social scientist must make any meaningful impact, especially in Africa then they must begin to finds ways of how to study human beings (Africans) effectively to knowing who they really are, their peculiarities, behavior, etc. to be able to adequately interpret them such that efficient and proficient answers and solutions can be found to their problems. 


\section{Critique}

Besides the issues raised and discussed already, it should be noted that illiteracy is one of the gigantic monsters helping oppression survive over a long period. The social scientists should devote concerted efforts at erecting a moral educational apparatus that will develop and enlighten the people to know their rights, duties and obligation to their fellow men and to the society. Simply put, a great deal of moral education that will go a long way in shaping the character and broaden the minds of the individuals should be put in place. There is an African proverb which says "a stone one see coming does not blind him". That is, that if the social scientist can find a way of establishing a programme, which will ensure that all Africans get education and therefore come out of ignorance then in a very short time the evil of oppression and suppression will be reduced to the barest minimum or even completely eradicated. Plato insisted on education to liberate the mind of the ignorant so that they can begin to see reality like those who have come out of the cave. (Russell, 1979)

Mostly the social scientists have failed to solve the problem of oppression in African because they have failed to examine the situation of Africa after colonialism. (Cartey, 1970) The exploitation and exploration of Africa, which heralded colonialism, went along way in devastating the continent and its people. Africans are still trying to find their feet occasioned from the many years they lost to the rude interruption by the west. Africa is a continent blessed with plenty of human and natural resources, which will go round for everybody.

Besides, the inductive method of study adopted by the social sciences is purely inadequate in studying the human society especially the African society. The adequate study method that should be adopted by the social sciences is the deductive method which proceeds from the universal stand point and ultimately narrows down to the particular or inductive perspective. There is always bound to be problem and inconsistency when the inductive method is used in the study of the human elements in the society. 


\section{Conclusion}

Philosophers have often referred to philosophy as the mother of all disciplines because of the normative nature of her study and some scholars find this irritating but the truth is that the discipline of philosophy critically questions every knowledge to ensure that whatever is accepted is, that which is sound, and incorrigible. (Stumpf, 1994).

The inability of the social sciences to adequately study and proffer timeless solutions to the problem of social oppression and suppression and other problems in Africa stem from the fact that the social sciences study the social society and make descriptive rather than prescriptive recommendations for solving these problems. Proffering descriptive solutions is not enough to address the seemingly complex problems facing Africans in particular and the world in general. The solutions needed are prescriptive solutions such that philosophy proffer. Descriptive solutions involves "what actually is" while prescriptive solutions deals with "what ought to be". If humans are studied as they actually behave then it would be difficult if not impossible to eliminate these inadequacies and shortcomings confronting him in his world. If they were to be studied, as they ought to be then many of their excesses would easily and readily be spotted and discarded. A good analogy is the relationship a doctor has with his patient. If the patient complains of headache the doctor prescribe drugs that should remove or stop the headache and if the patient wants to get better soonest he has to apply the drugs exactly the way the doctor prescribed them for him. If the patient does anything more or less he/she can eventually end up compounding his/her own problems. The doctor prescribes and the non-doctor describe because he is not the expert. His description is a blind guess that might or might not work. The doctor on the other hand knows exactly what the problem is and exactly what do to do, hence, he prescribe what the accurate antidote should be with very little or no room for errors. This he sure of his prescriptions because enough research has been conducted out as thoroughly as possible and has been tested to ensure practicability.

If the social sciences were to succeed in its quest for finding a lasting solution to the problems of man especially that of social oppression and suppression in Africa, then she has to acknowledge 
the relevance of philosophy as a prescriptive discipline that has the critical ability to dig deep and reflect on difficult issues and make meaningful postulations. Then the social sciences has to be prepared to work hand in hand with her particularly in making her finding available to philosophy for critical examination and reflection so that accurate prescription can be made in the right direction. The denial of the relevance of philosophy by the social sciences will not help the social sciences succeed in her study of the human society. By acknowledging and working closely with philosophy the social sciences will be eliminating the lacuna that it has always encountered in studying the human society from time to time. Since the social sciences cannot be accurate like the natural sciences there will always be a missing link of answers which philosophy can readily and easily find answers to so that its findings can be of relevance to the social society. The social sciences must not work in isolation of philosophy if concrete results were to be obtained. 


\section{References}

Abraham Lincoln, the famous American president who won election after nine times of contesting and loosing.

Appadorai, A.A. (1982) The Substance of Politics. (New York: Madras).

See Cartey, W. \& Kilson, M. (eds.) (1970) The African Reader: Independent Africa. (New York: Vintage Books,)

Evans- Pritchard, E.E. (1963) The Nuer: A Description of The Modes of Livelihood and Political Institutions of A Nilotic. (Oxford: Clarendon)

Hamlyn, D.E. (1977) The Theory of Knowledge. (London: Macmillan Press).

Hornby. A.S. (ed.) (2007) The Oxford Advance Learner's Dictionary of Current English, (Oxford: Oxford University Press,)

Iroegbu, P.O. (2000) Treatise on the Human Person. (Owerri: Eustel publications Limited,)

Kamenka, K. (1979) Marxism and Ethics, (Hong Kong: Macmillan and Co. Ltd.,)

Lloyd, G.E.R. (1973) Aristotle: The Growth and Structure of His Thought. (England: Cambridge University Press,)

Merton, R. (1979) Social Theory and Social Structure. (New York: Free Press,)

Odey, O.J. (2002) Democracy: Our Lofty Dream and Crazy Ambition, (Enugu: Snaap Press Limited,)

Omoregbe, J.I. (1998) Ethics: A Systematic and Historical Study. (Lagos: Joja Educational and Research and Publishers Limited,) Radcliffe, B. (1952) The Structure and Function in Primitive Society. (London: Cohen and West Reference is to two popular African leaders who were tyrants and dictators spent no less $35 y e a r s$ in power their countries and handed over to their children when they became too old to continue, they Mobutu sese seko of Zaire and Nysembe Eyadema of Togo.

Russell, B. (1996) History of Western Philosophy. (London and New York: George Allen \& Unwin)

Sills, D.L. (ed.) (1972) International Encyclopedia of Social Sciences, Vol. 5 (New York \& London: The Macmillan Company and The Press,) 
Stumpf, S.E. (1994) Philosophy: History and Problems. (New York: McGraw- Hill Books Inc.,)

Unah, J. I. (ed.) (1998) Metaphysics, Phenomenology and African Philosophy. (Ibadan: Hope Publications,) 